\title{
Physical Activity Measurement: Objective and Subjective Methods
}

\section{Fiziksel Aktivite Ölçümü: Objektif ve Sübjektif Yöntemler}

\author{
Sema Can \\ Faculty of Sport Sciences, Hitit University, Çorum, Turkey
}

S. Can

0000-0003-1931-2226

Geliş Tarihi/Date Received: 09.12.2018

Kabul Tarihi/Date Accepted: 15.03.2019

Yayin Tarihi/Published Online: 23.07.2019

Yazışma Adresi /

Corresponding Author:

Sema Can

Hitit Üniversitesi, Spor Bilimleri Fakültesi, Çorum, Turkey

E-mail: semacan@hitit.edu.tr

(C2019 Türkiye Spor Hekimleri Derneği. Tüm hakları saklıdır.

\begin{abstract}
The increase in sedentary lifestyle in daily life causes many chronic diseases, mainly cardiovascular and metabolic diseases. In order to protect and improve health, it is recommended that physical activity should be done at the desired level. However, in order to make suggestions for physical activity, first, it is necessary to determine the activity level by measuring the individual's physical activity. There are many methods of physical activity measurement, including subjective and objective ones. Among the commonly used methods, while questionnaires and logs constitute subjective methods, those making use of pedometers and accelerometers constitute objective methods. Each of these methods has advantages and disadvantages. Factors such as the reliability and validity of the measurement tool, acceptability by individuals, group size, age, gender, education, time, cost, and comorbidity must be considered when determining the measurement method based on the purpose of the research. In this context, in this review, commonly used physical activity measurement methods are examined, and the points to be considered in determining the measurement method are emphasized.
\end{abstract}

Keywords: Physical activity, measurement methods, health

\section{öz}

Günlük yaşam içinde sedanter yaşam tarzının artması başta kalp-damar ve metabolik hastalıklar olmak üzere birçok kronik hastalığa neden olmaktadır. Sağlığın korunması ve geliştirilmesinde fiziksel aktivitenin (FA) yeterli düzeyde yapılması önerilmektedir. Fakat bu önerilerinde bulunmak için öncelikle bireyin fiziksel aktivite ölçümünün yapılarak aktivite düzeyinin belirlenmesi gereklidir. Fiziksel aktivite ölçümünde sahada sübjektif ve objektif birçok yöntem kullanılmaktadır. Sık kullanılan yöntemlerden anketler ve günlükler sübjektif yöntemleri oluştururken, pedometre ve akselerometre gibi ölçüm araçları kullanımı ise objektif yöntemleri oluşturmaktadır. Bu yöntemlerin her birinin avantaj ve dezavantajı bulunmaktadır. Araştırmanın amacına göre ölçüm yöntemi belirlenirken ölçüm aracının güvenilirliği, geçerliği, bireyler tarafından kabul edilebilirliği, grubun büyüklüğü, yaş, cinsiyet, eğitim, zaman, maliyet ve komorbidite gibi unsurlar göz önünde bulundurulmalıdır. Bu doğrultuda bu derlemede sahada sık kullanılan fiziksel aktivite ölçüm yöntemleri incelenmiş ve ölçüm yöntemi belirlenirken dikkat edilmesi gereken noktalar vurgulanmıştır.

Anahtar sözcükler: Fiziksel aktivite, ölçüm yöntemleri, sağlık

Available at: http://journalofsportsmedicine.org and http://dx.doi.org/10.5152/tjsm.2019.144

Cite this article as: Can S. Physical activity measurement: Objective and subjective methods. Turk J Sports Med. 2019;54(4):296-307. 


\section{GíRIş}

Fiziksel aktivite (FA) "İskelet kaslarının kasılması ile ortaya çıkan enerji harcanmasıyla sonuçlanan bedensel hareket" olarak tanımlanmaktadır (1). Bilimsel olarak bireyin düzenli fiziksel aktivite veya egzersize verdiği yanıtın ölçümü 18. yy.a dayanmaktadır. Sir John Floyer 1707 yılında ilk kez egzersiz sırasında kalp atım hızının ölçülmesine izin veren bir saat geliştirmiştir (2). Edward Smith, 1850'de Londra'da çalışan mahkumlar ile yaptığı çalışmada karbondioksit üretimini ve kalp atım hızını ölçerek yorucu aktivitede bulunma cezasının biyolojik olarak olumsuz etkisi olduğunu belirtmiştir (3). 20. yy.ın ilk yarısında ise, fizyologlar egzersizin tipi, süresi ve şiddetine göre değişimlerle birlikte, birçok doku, organ, ve sistem üzerindeki akut ve kronik yanıtlarını incelemişlerdir. $\mathrm{Bu}$ araștırmaların birçoğunda egzersizin fiziksel uygunluğun bazı bileşenlerini geliştirdiği belirtilmiş fakat sağlık üzerine etkisine daha az vurgu yapılmıştır (3).

Fiziksel aktivite ve halk sağlığı alanındaki araştırmalar ise ilk olarak 1950'li yıllarda yapılmaya başlanmıştır. Londra'da iki katlı otobüslerde çalışan şoförler ile bilet satmak için günde belirli mesafeyi yürüyerek geçiren bireyler üzerinde yapılan araştırmada, oturarak yapılan mesleklerde koroner kalp hastalıklarından kaynaklı mortalite oranlarının daha fazla olduğu, fiziksel olarak aktif erkeklerin daha az akut koroner arter hastalığı yaşadığı vurgulanmıştır $(4,5)$. Günümüze kadar, sedanter davranış veya inaktif yaşamın kardiovasküler, kas-iskelet sistemi ve metabolik hastalıklar gibi birçok sağlık sorunu ile ilişkili olduğu belirtilmiştir.

Büyük epidemiyolojik araştırmalar ise, 197080'li yıllarda yapılmaya başlanmış ve bahçe işleri, yürüyüş gibi aktivitelerin orta şiddette düzenli yapılmasının sağlığın korunmasında önemli olduğu, bununla birlikte FA'yı yaşam tarzı haline getirmenin veya gün boyunca aktif olmanın önemine değinilmiștir $(3,6)$. Bu doğrultuda, Dünya Sağlık Örgütü (WHO) 5-17 yaş grubu için, günde en az $60 \mathrm{dk}$ orta-şiddetli aktivite, 18 yaş ve üzeri yetişkinler için, haftada en az $150 \mathrm{dk}$ orta şiddetli (30 dk x 5 gün) veya haftada en az $75 \mathrm{dk}$ şiddetli aerobik aktivite önermektedir (7). Aerobik aktiviteye ek olarak haftada iki gün büyük kas gruplarını içeren kuvvet çalışmaları, eklem hareket açıklığını artırmak için esneklik ve özellikle yaşlı bireyler için denge egzersizleri yapılması önerilmektedir (7). Halk sağlığı kampanyası kapsamında ise sağlıklı yetişkin bireyler için günde ortalama 10000 (3000-3500 adım/30 dk) ve üzeri adım atılması önerilmektedir.

Sedanter davranış (SD); oturma veya yatma pozisyonunda $\leq 1.5$ MET (Metabolic Equivalent of Task) enerji harcaması gerektiren aktiviteler olarak tanımlanmaktadır (8). Başka bir tanıma göre SD, dinlenme seviyesinin üzerinde, uzanma, yatma, oturma, televizyon izleme, bilgisayar kullanma gibi enerji harcamasında artış olmayan pozisyonları içeren aktivitelerdir (6). Düşük yoğunluklu FA genellikle sedanter davranış ile birbirinin yerine kullanılmaktadır fakat ayırıcı yönü enerji harcamasının 1.6-2.9 MET arasında olmasıdır (Yavaş yürümek, yazı yazmak vb) (9). Buna karşın, spor ve egzersiz literatüründe "sedanter" terimi genellikle ortaşiddetli fiziksel aktivitenin yokluğunu tanımlamak için kullanılmakta, önerilen düzeyde fiziksel aktivite yapmayan bir birey "sedanter" olarak tanımlanmaktadır (8).

Sedanter davranış tanımı ile ilgili ortak bir uzlaşı olmadığından sedanter davranışı ölçmek de zordur (10). Literatürde SD veya düşük düzeyde fiziksel aktivitenin ölçümü ile ilgili araştırmaların çok fazla olmadığı ve genellikle orta-yüksek şiddette yapılan egzersizin insan fizyolojisi üzerindeki etkisinin araştırma konusu olduğu belirtilmiştir (6). Fakat, günümüzde sedanter yaşam prevelansının yüksek olması, doğru verilere ulaşmak için doğru ölçüm aracı seçmenin önemini göstermektedir.

Fiziksel aktivite ölçümünde kullanılan birçok yöntem bulunmaktadır. Bu ölçüm yöntemleri kriter (altın standart) yöntemler, objektif ve sübjektif yöntemler olmak üzere üç bölümde incelenmektedir. Kriter yöntemler; direkt kalorimetri, indirekt kalorimetri, çifte 
etiketlenmiş su, doğrudan gözlemden oluşmaktadır. Akselerometreler, pedometreler ve kalp atım hızı yöntemi objektif yöntemleri oluştururken, görüşme yöntemiyle veya kendini rapor etme/değerlendirme yöntemiyle yapılan anketler ve günlükler sübjektif yöntemleri oluşturmaktadır. Fiziksel aktivitenin değerlendirilmesi için ilk adım, "egzersiz gibi yapılandırılmış bir aktiviteyi mi ölçmek ya da günlük aktiviteler gibi toplam fiziksel aktiviteyi mi ölçmek?" gibi sorulara cevap vererek araștırmanın amacı doğrultusunda hareket etmektir. Ayrıca, FA'nın özellikleri (tip, sıklık, süre ve şiddet), alanları (meslek, ev işleri, ulaşım ve boş zaman) ve ölçü birimini (kcal, MET, orta ve șiddetli FA) tanımlamak da önemlidir (11,12).

Elli yıldan fazla süredir FA ile kronik hastalık ve mortalite arasındaki ilişki sübjektif yöntemlerle araştırılmış olsa da son 10-15 yıldır sübjektif yöntemlere ek olarak objektif ölçüm yapabilen pedometre ve akselerometre gibi teknolojik araçların arttığı görülmektedir $(3,13)$.

\section{Objektif Yöntemler}

Teknolojinin hızlı gelişimi, pedometre ve akseloremetre gibi objektif ölçüm araçlarının ortaya çıkışını beraberinde getirmiştir. $\mathrm{Bu}$ artış objektif ölçüm araçlarının maliyetlerinde düşüş sağlayarak sübjektif kullanılan yöntemlere alternatif olmalarını sağlamıştır. $\mathrm{Bu}$ araçlar yürüyüşe duyarlı olup fiziksel aktivite kayıtlarını sürekli ölçebilmekte ve farklı egzersiz yoğunluklarında ölçüm yapabildiklerinden tahmini bir enerji hesaplaması da vermektedirler $(14,15)$. Daha çok sedanter davranış ile ilgili ölçüm yapabilen bu cihazlar ile aktivitenin tipi hakkında ayrıntılı bilgi alınamamaktadır (3). National Health and Nutrition Examination Survey (NHANES) 20032006 araştırmasında, sübjektif ve objektif araçların birbirinin tamamlayıcısı olduğu belirtilmiş ve akselerometrelerin bu araștırma ile popülaritesi artmıştır (10). Ayrıca sübjektif ve objektif ölçüm araçlarının birlikte kullanılmasının daha doğru veriler sağladığı da belirtilmiştir (16).

\section{Pedometreler}

İlk olarak Japonya'da ortaya çıkan, en basitten en komplekse doğru birçok çeşidi bulunan pedometreler, adım saymak için geliştirilmiş ölçüm araçlarıdır. Sedanter hayat yaşayan bireyler için adım sayısı önemli bir gösterge olarak kabul edilmektedir (14). Pratik kullanım, düşük maliyetli oluşu ve kısa süreli fiziksel aktiviteleri (genellikle anket yöntemi ile gözden kaçırılmış aktiviteler) kayıt edebilme yeteneği bu cihazları popüler hale getirmiştir. Fiyatı, mekanizmasına ve özelliğine (saat, hafıza, yazılım vb.) göre değișebilen pedometreler, dikey olarak yapılan hareketleri ölçebilmektedir $(17,18)$.

Ortaya çlkan sonuç markalara göre değișebilmekle birlikte FA'nın sıklığını, süresini ve şiddetini doğrudan hesaplayamamaktadır. Pedometreler, orta şiddetli yürüyüş gibi, dikey ileri hareket gerektiren aktivitelerde en doğru sonucu vermektedir. Koşu, bisiklet, kuvvet egzersizleri, su aktiviteleri, sedanter geçen zaman veya sadece yatay hareketleri içeren üst vücut hareketleri sırasında ortaya çıkan aktiviteleri kayıt edememektedir. Farklı tipte aktivite yapan çocuklar ve yavaş yürüyüş esnasında özellikle yaşlı bireylerde kullanımı önerilmekle birlikte, çok yavaş yürüyen yaşlılarda doğru ölçüm yapamadığı da belirtilmektedir (19). Pedometreler akselerometrelere göre daha az veri depolama kapasitesine sahiptir ve kullanicilarda davranışlarda değiş̧ikliğe neden olabilmektedir. Ayrıca, araştırma boyunca, katılımcılar pedometreleri kaybedebilir veya kırabilir. Bazı pedometreler ise verileri depolayamadığından, katılımcıların günlük adım sayısını kendileri kaydetmeleri sonuçların objektifliğini olumsuz etkileyebilir (20).

Ölçüm yapılmadan önce pedometrelerin maliyeti, mekanizması ve duyarlılığı göz önünde bulundurulmalıdır. Güvenilirliği ve geçerliği cihazın modeline, türüne göre değişebilmekle birlikte adım ölçerlerin \%25-45 oranında az veya fazla ölçüm yapma olasılığı vardır $(17,18)$. Bu hatayı en aza indirmek için araştırmacıların kullandıkları cihazların güvenilirlik ve geçerlik 
çalışmaları hakkında bilgi sahibi olmaları önemlidir (18). Genel olarak pedometreler adım sayısını, mesafe ve enerji harcaması hesaplamasına göre daha doğru ölçen cihazlar olarak kabul edilmektedir (21).

Pedometrelerin farklı bölgelere (bel, uyluk, cep, el ve ayak bileği) takılan modelleri olup genellikle uyluğun orta hattına takılmaktadır. Takılan bölge adım sayısını etkileyebilmektedir. Örneğin, bel çevresi geniş olan bireylerde pedometrelerin bel bölgesine bir bant ile sabitlenmesi durumunda dahi yer değiştirmesinin sonuçların doğruluğunu etkileyebileceği belirtilmiştir (22). Ayrıca teknolojiyle birlikte, akıllı telefon uygulamalarında yer alan adım sayısı programları ile de ölçüm yapılabilmektedir.

Araştırmacılar, pedometrelerin en az üç ardışık gün (iki hafta içi, bir hafta sonu) takılmasını, daha doğru ve güvenilir bir ölçüm yapmak için, katılımcların standart bir protokole uyarak, cihazları ortalama 5-7 gün takarak daha doğru sonuçlar elde edilebileceğini belirtmektedir $(14,23)$. Bu yaklaşım, hafta içi ve hafta sonu arasındaki FA'daki değişkenliğin hesaplanmasına olanak sağlayarak ölçüm hatasını en aza indirebilmektedir.

\section{Akselerometreler}

Akselerometreler, pedometrelerden daha karmaşık, her yaş grubuna uygulanabilen, vücut hareket yoğunluğunu, vücudun hızlanma ve yavaşlamasını ölçebilen cihazlardır. Akselerometreler saniye veya dakika odaklı izlem yaparak aktivitenin frekansı, süresi ve yoğunluğu hakkında bilgi vermektedir $(24,25)$. Akselerometrelerin; fazla veri toplaması, sonuçların güvenilirliği, yönetim kolaylığı gibi avantajlarından dolayı sedanter davranışın ölçülmesinde son yıllarda önemi artmıştır.

Akselerometreler, tek veya çok eksenli özelliklere sahiptir. Ilk kullanılan akselerometrelerin tek eksenli olduğu ve yalnızca dikey eksende ölçüm yaptığı bilinmekdir. Günümüzde ise teknolojinin gelişmesiyle kullanılan akselerometrelerin birçoğu iki (vertikal ve mediolateral veya vertikal ve anterior-posterior), veya üç farklı eksende (vertikal, mediolateral ve anteriorposterior) ölçüm yapabilmektedir $(26,27)$. Hem gençlerde hem yetişkinlerde FA'yı ölçmede tek eksenliler ve çok eksenliler arasında tutarlı bir fark olmadığı belirtilen görüşler arasındadır (28). Fakat çok eksenli akselerometrelerin özellikle çocuklarda, farklı eksenlerde hareket içeren aktivitelere katılmaları nedeniyle kullanılması daha çok önerilmektedir (29).

Akselerometrelerde çeşitli aktivite yoğunluklarını tanımlamak için "kesim noktaları" olarak adlandırılan eșik değerler kullanılmaktadırlar. Bu eşik değerler FA'nın tipi, yoğunluğu, süresi, alanları ve yaş grubuna (çocuk, adolesan, yetişkin ve yaşlı) göre değişebilmektedir. $\mathrm{Bu}$ farklılıklar kullanılan aktivite monitörlerinden çlkan sonucu doğrudan etkilemektedir $(24,25,30)$. Akselerometrelerin aktivite sayısı ile enerji harcaması arasındaki ilişki, uygulanan kesim noktasına bağlıdır. Farklı kesim noktaları seçmek ölçüm sonucunu (sedanter, düşük, orta, yüksek) etkileyebilmektedir (26).

Veri analizleri için sayıların toplandığl, araştırmacı tarafından önceden tanımlanabilen 1-60 s arasında değişen zaman aralıkları bulunmaktadır (31). Genellikle aktivite sınıflaması (sedanter, hafif, orta, şiddetli) için 60 s'lik zaman aralığı kullanılmaktadır. Bu zaman aralıklarının seçimi, aktivite monitörünün kullanıldığı popülasyona da bağlı olabilir. Örneğin, araştırmacılar, çocukların aralıklı ve şiddetli aktivitelerden dolayı FA'yı sinıflandırmak için 15-30 s gibi kısa zaman aralıklarının kullanıldığı (30), yetişkin ve yaşlı bireylerde, genellikle 60 s'lik zaman aralığ kullanıldığı görülmektedir (32). Ölçüm sonucu elde edilen sayılar doğrudan ivmenin büyüklügü ile ilgilidir ve ham verilerden elde edilen sayllar metrik ölçüme dönüştürülerek enerji harcaması (kcal, MET), sedanter davranış ile geçirilen zaman, hafif, orta ve şiddetli yoğunlukta FA kategorileri elde edilebilir (11). $\mathrm{Bu}$ sayılar/veriler cihaza ve üretici firmaya göre değişebileceğinden farklı ölçüm yöntemlerinden ve markalardan elde edilen ölçüm sonuçlarının 
doğrudan karşılaştırılması önerilmemektedir (26).

Akselerometrelerin, s/dk odaklı izlem yapması, aktivitenin yoğunluğunu belirlemesi, çocuklarda uygulanabilirliği, statik ve dinamik hareketleri ölçme, büyük bellek kapasitesine sahip olması avantaj olarak görülürken; teknik uzmanlık, özel donanım, yazılım ve bireysel programlama gerektirmesi dezavantaj olarak kabul edilmektedir. Bununla birlikte, bazı akselerometrelerin yüksek maliyetli olması büyük popülasyonlu araştırmalarda kullanımlarını sinırlayabilmektedir. Ayrıca reaktiviteye neden olabilir, vücut pozisyonu (oturma, yatma, ayakta ve durma gibi) ve yürümenin şiddetini ayırt edemeyebilirler (26). $\mathrm{Bu}$ nedenle çalışmalarda kullanılan veri toplama protokolleri, takıldığı bölge, takma süresi, takılmayan sürede kullanılacak FA ölçüm yöntemleri de verilerin doğruluğunu ve araştırma sonucunu etkileyebilir.

FA değerlendirilmesinde en yaygın kullanılan akselerometreler arasinda ActiGraph, ActivPAL ve Actical bulunmaktadır $(33,34)$. Cihaz seçimini etkileyen birçok faktör bulunmaktadır ve tüm cihazların avantaj ve dezavantajları vardır $(17,35)$. Monitörün seçiminde, araştırmanın amacı, ölçüm yapılacak birey sayısı, eğitilmiş personel, cihazın maliyeti, kalitesi, güvenilirliği, kullanım protokolleri, kalibrasyonu, verilerin analizi, kullanılan diğer veri kaynakları ile entegrasyonu göz önünde bulundurulmalıdır (35-37). Fakat akselerometrelerin, en iyi şekilde nasıl kullanılacağı, monitör seçimi, hangi bölgeye kaç gün takılacağı veya verilerin nasıl yorumlanacağı konusunda fikir birliği yoktur.

Akselerometreler, el bileği, üst kol, bel ve ayak bileği gibi farklı bölgelere takılarak ölçüm yapabilmektedir. Çoğu akselerometreler ayaktan hareketliliği doğru bir şekilde ölçmek için geliştirilmiş olup genellikle kütle merkezine yakın olarak takılmaktadır $(22,27,38)$ ve takılmış olduğu bölgeye göre ölçüm sonuçları değişebilmektedir. Örneğin, yaşlı bireylerde, mültipl skleroz ile birlikte kaslarda güçsüzlük ve denge kaybı gibi hareket sinırlılığı olan bireylerde ayak bileğine takıldığında sonuçların değișebileceği belirtilmiştir (39). Akselerometrelerin en büyük dezavantajı ise üst extremiteye takıldığında; ağırlık kaldırma, bisiklet, izometrik egzersizler, bazı ev işleri gibi daha az beden hareketi gerektiren aktiviteleri düşük düzeyde tahmin etmesidir (25).

Bir bireyin FA düzeyini doğru ölçmek için monitörlerin belirli bir sürede takılması gerekmektedir. Akselerometrelerin kaç gün takılacağı konusunda fikir birliği yoktur. Akselerometrelerin hangi bölgeye kaç gün takılacağı ve kişinin cihaza uyumu doğru verilerin alınması için önemlidir (38). Popülasyona göre değişmekle birlikte 14-21 gün takılmasının ölçüm sonuçlarının güvenilirliğini arttıracağı belirtilmektedir $(36,37)$. Genellikle takılabilen süre günde ortalama 10 saattir (38). Fakat International Study of Childhood Obesity, Lifestyle and the Environment (ISCOLE) çalışmasında, katılımcıların aktivite monitörlerini 24 saat takmaları önerilmiş, bu yaklaşımın çocuklarda uygulanarak eksik verileri en aza indirgemede etkili olduğu belirtilmiştir (40).

Cihazı takma süresi, uyku süresini ve cihazın takılmadığı süreleri kapsamamaktadır. Akseloremetre ölçümlerinde sıklıkla kayıp veri olduğu için, cihazın takıldığı ve takılmadığ zamanları belirlemeye yönelik olarak aktivite günlükleri kullanılması kabul görmektedir $(34,41,42)$. Ardışık günler olmak koşuluyla genellikle yedi gün önerilmektedir (23). Örneğin, Sense Wear Armband (SWA) cihazı için yedi gün 24 saat $\% 95$ ve üzeri takılması durumunda doğru ölçümün yapılabileceği belirtilmiştir (23). Ayrıca çocuk ve adolesanları 4-9 gün izlemek gerekli olabilirken, yetişkinlerde bu sayı ortalama 3-5 gün olabilir (28). Fakat büyük ölçekli çalışmalarda, akselerometrelerin uzun süreli takılması ve takip edilmesi zor olduğundan, verilerin eksik toplanması olası karşılaşılan durumdur. Böyle bir durumda araştırmacılar adolesan ve çocuklarda akselerometrelerin üç hafta içi, bir de hafta sonu olmak üzere en az dört gün, yetişkinler için ise iki hafta içi, bir de hafta sonu olmak üzere en az üç gün takılmasını önermektedir $(22,23)$. 
Tablo 1. MET skorlarına göre akselerometre kesim noktalarının sınıflandırılması (26)

\begin{tabular}{lll}
\hline $\begin{array}{l}\text { Aktivite } \\
\text { yoğunluğu }\end{array}$ & MET & $\begin{array}{l}\text { Aktivite sayısı, } \\
\text { dk }^{-1}\end{array}$ \\
\hline Hafif & $\leq 3.00$ & $\leq 1951$ \\
Orta & $3.00-5.99$ & $1952-5724$ \\
Zor & $6.00-8.99$ & $5725-9498$ \\
Çok zor & $\geq 9.00$ & $\geq 9499$ \\
\hline
\end{tabular}

Araştırmada akselerometreler kullanıcılara dağıtılmadan önce kullanıma hazır duruma getirilmeli; pil, batarya durumu kontrol edilerek ölçüm süresince yeterli olabileceğinden emin olunmalıdır. Genellikle katılımcıların cihazı aldıkları günü takiben saat 00:00'da başlamaları önerilmektedir. Verileri doğru analiz etmek ve tutarsız verileri en aza indirmek için, yataktan kalkma zamanı, monitörün takıldığı ve çıkarıldığı zaman, yatma zamanı gibi bilgilerin kaydı için izleme günlükleri kullanılmalıdır. Büyük ölçekli araștırmalarda, ölçüm hakkında bilgilendirme yazıları için broşür, e-posta veya kısa mesajlar gönderilebilir. Ayrıca katılımcılara doğru ve yeterli süre takmaları için hediye, parasal destek gibi özendirici unsurlar kullanılması önerilmektedir (26).

\section{Direkt Gözlem}

Doğrudan gözlemde, bağımsız bir gözlemci FA davranışlarını izler veya video ile kaydeder. $\mathrm{Bu}$ yöntem ile kaliteli veriye ulaşılır; aktivitenin sıklığı, şiddeti, süresi, tipi hakkında ayrıntılı bilgi elde edilebilir ve esnek skorlama yapılabilir. Çocuk ve ergenlerde popüler olan bu yöntem, beden eğitimi dersleri, sınıf, park gibi alanlarda uygulanır ve belirli aktiviteler, hava koşulları, mekan ve zaman gibi bilgiler ayrıntılı kayıt edilebilir. Gözlemciler, yöntemi nasıl uygulayacakları konusunda mutlaka eğitilmelidir ve gözlemciler arasında uyum olması nitelikli ölçüm yapılması açısından önemlidir (43). Yüksek maliyet, sınırlı izleme süresi, gözlemci eğitimi, verileri kodlamada zorluklar, etik onay almanın güçlügü, gözlemcilerin katılımcı davranışları üzerinde olası reaktivite etkileri gibi dezavantajları vardır $(43,44)$. The System for Observing Fitness Instruction Time (SOFIT) yöntemi, en sik kullanılan yöntemlerden biridir. Bir öğrenci rastgele seçilerek $5 \mathrm{dk}$ 'llk sürede, her $30 \mathrm{~s}$ 'de bir yaptığ durma, yürüme ve çok aktif olarak beş ayrı kategoride kodlanır. SOFIT ile güvenilirliği yüksek sonuçlar elde edilebilmektedir (45).

\section{Sübjektif Yöntemler}

Araștırmacılar iș, ulașım, ev ișleri, serbest zaman gibi FA alanlarını ölçmek için pratik, geniş popülasyonda kolayca uygulanabilen, maliyeti düşük olan sübjektif yöntemleri tercih etmektedir. Anketler, FA parametrelerinin (aktivitenin tipi, süresi, sıklığı, şiddeti) nasıl elde edildiğine (yüz yüze görüşme, e-posta, telefon vb.) ve raporlanışına (aktivite skorları, zaman, kalori vb.) göre farklılık göstermektedir. İki tip sübjektif yöntem (anketler ve günlükler) bulunmakta olup kendini rapor yöntemi veya görüşme yöntemiyle uygulanan çok sayıda anket bulunmaktadır $(11,46)$.

\section{Anketler}

Hatırlamaya dayalı FA anketleri, genellikle yetişkinlerin ulusal FA rehberleri önerilerine uyup uymadıklarını, aktivite seviyelerinin yeterli olup olmadığını ve fiziksel aktivite davranış değişikliklerini takip etmek için kullanılmaktadır. $\mathrm{Bu}$ anketler, genellikle FA düzeyini "son 24 saat", "son yedi gün", "genellikle" ifadeleri kullanarak ölçüm yapmaktadır. Ortalama 10-20 sorudan oluşan bir form ile aktivitenin türü, sıklı̆̆l, süresi ve şiddetine ilişkin bilgi elde edilebilir $(47,48)$. Sorulan aktivite türleri arasında orta-şiddetli aktiviteler, oturma, merdiven çıkma, yürüyüş gibi aktiviteler bulunmaktadır. Fiziksel aktivitenin yoğunluğu genellikle MET olarak ifade edilmekte olup aktivite puanlarına göre hesaplama yapılmaktadır (49).

En fazla kullanılan ankete örnek Uluslararası Fiziksel Aktivite Anketi (IPAQ) verilebilir. Uzun ve kısa formları bulunan ankette katılımcılar bir önceki hafta gerçekleştirdikleri aktivitelerin süresini ve sıklığını rapor etmektedir. Yedi 
sorudan oluşan IPAQ-kısa form alanları sinırlıdır ve daha çok orta-şiddetli FA'yı değerlendirmektedir. Yaşları 18-65 arası olan bireylerde, yaklaşık 70 ülkede kullanılan IPAQ, farklı kültürlere ve dillere göre uyarlanmış, güvenilirliği ve geçerliği elde edilmiştir (48). Ülkemizde Öztürk (50) anketin üniversite öğrencileri üzerinde güvenilirlik ve geçerlik çalışmasını yapmıştır.

Ayrıca, Karaca ve ark. tarafindan IPAQ-kısa formun 20-60 yaş arasındaki obez yetişkinler için güvenilir ve geçerli olduğu, fiziksel aktivite düzeyinin belirlenmesinde kullanılabileceği gösterilmiştir (51). Ülkemizde "Fiziksel Aktivite Değerlendirme Anketi (FADA)", yetişkinler için geçerliği ve güvenilirliği elde edilen ilk ankettir. "Fiziksel Aktivite Alışkanlığını Değerlendirme Anketi", "7-günlük Fiziksel Aktivite Değerlendirme Anketi (7-g-FADA)" ve "24 saatlik Fiziksel Aktivite Değerlendirme Anketi (24-s-FADA)" yetişkinler için geliştirilen ülkemize özgü diğer anketlerdir $(52,53)$. WHO tarafından önerilen Global Fiziksel Aktivite Anketi (GPAQ) ise; rekreasyon, meslek ve ulaşım ile ilgili aktiviteleri daha ayrıntılı özetleyen anket olarak kabul edilmektedir (54).

Bireyin fiziksel aktivite düzeyini global düzeyde 2-4 maddelik sorularla hızlı ve pratik bir şekilde değerlendirilen, ayrıca önerilen fiziksel aktivite düzeyini (150 dk orta şiddetli fiziksel aktivite) karşılayıp karşılamadığını veya bireyi aktif/inaktif olarak kategorize etmek için kullanılan anketler de bulunmaktadır. Kendini rapor etmeye dayalı evrensel anketler yönetim kolaylığı, kısa oluşu ve fiziksel aktivite skorunu belirleme özellikleriyle birçok klinik ortamda, epidemiyolojik araştırmalarda kabul görmektedir (11). Genel olarak hatırlamaya dayalı anketler epidemiyolojik araştırmalarda, çeşitli hastalık sıklıklarını ve sağlığı geliştirici davranışları incelemekle birlikte, inaktivitenin mortaliteye ne düzeyde katkıda bulunduğunu belirlemek için kullanılmaktadır (55). Ayrıca, geçmiş dönemlerde bireyin tahmini FA yapma durumunun ölçülmesiyle kişinin mevcut sağlık durumuna ilişkin bilgi edinmeyi sağlayabilen anketler de bulunmaktadır (56).
Genel olarak anketlerin ucuz maliyet, dağıtım ve yönetim kolaylığı, şiddetli aktiviteyi ölçmede doğruluk, fiziksel aktivitenin kategorilerini belirleme (düşük, orta, yüksek) gibi avantajları vardır. Anketlerin düşük, orta şiddetli aktiviteleri değerlendirirken doğruluğunun daha az olması, aktivite düzeyini yüksek rapor etme olasılığı, tutarsız sonuçlar vermesi; objektif yöntemlerle karşılaştırıldığında ise, orta şiddetli aktivitelerde gerçek değerinden daha yüksek değerler vermesi zayıf yönleri olarak kabul edilmektedir $(19,46)$.

Kendini rapor etme yöntemiyle uygulanan anketler 10-11 yaşın altındaki çocuklarda önerilmemektedir. Örneğin, "Youth Risk Behavior Survey" anketinin uygulandığı çalışmada lise öğrencilerinin \%35'inin FA önerilerini karşıladığı belirtilirken (57), akselerometreler ile yapılan ölçümlerde bu oran \%3-10 arasında bulunmuştur (58). Bu nedenle genç bireylerde objektif yöntemlerin kullanılması (58) ve basit, kısa olan anketlerin tercih edilmesi ölçüm hatasını en aza indirebilir. Kendini raporlama yöntemiyle uygulanan anketler, akselerometreler ve kalp atım hızı monitörleri gibi objektif yöntemlerle geçerliliği kanıtlandıktan sonra kullanılmalıdır. Ayrıca, okur-yazar olmayan veya eğitim düzeyi düşük bireylerde anketlerin anketörler tarafından uygulanması doğru ölçüm yapmada önemlidir $(19,46)$.

Sübjektif yöntemler genellikle büyük popülasyonlu çalışmalarda tercih edildiğinden, soruları sorma şekli, anketin karmaşıklığı, yaş, mevsimsel faktörler de sonuçları etkileyebilmektedir. Ayrıca, ev işleri, çocuk bakımı ve ayakta yapılan işler gibi bazı aktivitelerin özellikle sedanterlerde ayrıntılı kayıt edilemediği, bazı sorulara yuvarlak yanıtlar verildiği görülmektedir. Örneğin, yürüyüş sedanter bireylerin aktif olup olmadığını belirlemede en önemli aktivite türüdür. Çünkü yürüyüş hem popüler bir serbest zaman aktivitesi hem de günlük en fazla tercih edilen bir aktivite tipidir. Çoğu hatırlamaya dayalı anketlerde yürüme "en az güvenilir" olarak hatırlanan fiziksel aktivite tipi olarak kabul edilmektedir. Özellikle yaşlı 
bireylerde hatırlama probleminden dolayı anketler güvenilir bulunmamaktadır $(46,59)$.

\section{Aktivite Günlükleri}

Aktivite günlükleri, katılımcıların belirli periyotlarda ayrıntılı olarak tüm aktivitelerin kaydını tutmasını gerektiren, geçerlilik çalışmalarında kullanılan kriter metod olarak kabul edilmektedir $(34,60)$. Kayıt edilen bilgi türü değișebilmekle birlikte genellikle aktivitenin tipi, şiddeti, başladığı ve bittiği saat kayıt edilir ve aktivite listesine göre şiddetin hesaplanmasında MET skor listesi kullanılır (49). Bu yöntem ile ayrıntılı veri elde edilerek anketlerin hatırlama problemleri gibi sinırlılıklarının üstesinden gelinebilir. Bouchard'ın fiziksel aktivite kaydı (BAR) katılımcıların her $15 \mathrm{dk}$ da bir aktivitelerini raporladığı geniş kullanımı olan bir aktivite kaydı örneğidir (61). Aktiviteler, toplam harcanan enerji puanını elde etmek için 1 'den 9'a kadar (1= sedanter, 9= şiddetli/yüksek şiddetli aktivite) sınıflandırılmıștır $(49,62)$. Elde edilen sayılar toplanarak MET değerleri ile çarpılır ve tahmini günlük enerji harcaması (kcal/ $/ \mathrm{kg}^{1}$ ) hesaplanabilir (49).

\section{Fiziksel Aktivite Ölçümü ve Etkileyen Faktörler}

Bir ölçüm aracının seçimi; araştırmanın amacı, popülasyon, ölçüm aracının güvenilirlik ve geçerliği, ölçüm süresi, zaman ve maliyet gibi birçok faktöre bağlı olmakla birlikte yaş, cinsiyet, vücut ağırlığı ve komorbidite gibi birçok faktör de etkileyebilmektedir $(11,12)$.

\section{Yaş}

Yaşa göre aktivitenin sıklığı, süresi, bireyin algl düzeyi, dikkat süresi farklılık gösterebilir. Örneğin çocuklar genellikle kısa süreli, yüksek şiddetli FA davranışları sergilediklerinden her fiziksel aktivite yöntemini kullanmak uygun değildir. Çocuklar için en fazla tercih edilen yöntem akselerometreler (activPal gibi), direkt gözlem, Bouchard'ın fiziksel aktivite kayıtlarıdır (63). Bununla birlikte SWA gibi çok sensörlü bir akselerometrenin, sedanter, düşük ve orta düzeydeki aktivitelerde daha çok geçerliği olduğundan çocuklara özgü algoritmalar geliştirildikten sonra kullanılması gerektiği belirtilmiștir $(64,65)$.

Yetişkinlerin sürekli olarak düşük, fakat sabit hızda FA (yürüme gibi) ve işyerinde sedanter aktivite gösterme olasılıkları daha yüksek olduğundan (66), kendini raporlamaya dayalı ölçüm araçları önerilebilir fakat çocuk ve yaşlılar için sinırlılıkları gözönünde bulundurulmalıdır. Yürüyüş en fazla tercih edilen aktivite olduğundan yetişkin veya yaşl bireyler için yürüyüşü doğru ölçebilen ölçüm araçları kullanılmalıdır. Özellikle kayıt yapabilme özelliği olmayan pedometreler çok yavaş yürüme hızı olan yaşlı popülasyonda önerilmemekte olup activPal gibi akselerometreler kullanılabilmektedir $(67,68)$.

\section{Cinsiyet}

Cinsiyete özgü FA ölçümü yapılması yaş, vücut ağırlı̆̆l, komorbidite, kültür ve ülkeye göre farklılık gösterebilir (69). Örneğin kadınlar erkeklere göre yürüyüş veya düşük $F A^{\prime} y a$ katılmaya, erkekler ise şiddetli FA'ya katılmaya daha isteklidir. Kadınlar için düşük yoğunluklu aktivitelerde fiziksel aktivite kayitları ve akselerometrelerin (Tritrac vb.) geçerliliğinin tartışmalı olduğu $(63,70)$, adım sayısı ölçümünde pedometrelerin daha doğru sonuçlar verdiği, düşük yoğunluklu fiziksel aktivitenin birçok alanını değerlendiren raporlama yöntemlerinin doğru sonuç elde etmek için kullanılabileceği belirtilmektedir (63).

\section{Vücut ağırlı̆̆ı}

Genel olarak, hatırlamaya dayalı ölçüm araçlarının inaktif ve obez bireyler arasında daha az doğru sonuç verdiği, obezlerde obez olmayanlara göre aktivite seviyesini düşük veya yüksek tahmin ettiği belirtilmiştir (63). Yüksek beden kütle indeksi (BKİ) ile inaktif yaşam tarzının bir arada olması enerji harcamasının doğru tahmin edilememesine neden olmaktadır ve obezlerin inaktif yaşamları nedeniyle (71), pedometrelerin hatalı sonuç verebileceği de belirtilen görüşler arasındadır (72). Fakat ActivPAL gibi bazı akselerometrelerin bu popülasyonda ölçüm yaparken kullanılabileceği, TriTrac gibi akselerometrelerin ise obezlerde 
sedanter davranışın değerlendirilmesinde sinırlılığı olduğu vurgulanmıştır $(33,41)$.

\section{Psikiyatrik Hastalıklar ve Komorbidite}

İleri derece mental hastalığı olan bireylerde, dikkat süresinde azalma, bellek problemleri, kavrama yeteneği problemlerinin olması seçilecek yöntemi etkileyebilmektedir ve $F A$ ölçümünde hatalar olabileceği göz önünde bulundurulmalıdır $(73,74)$. Bilișsel bozukluğu olan bireylerde, uzun, karmaşık, hatırlamaya dayalı anketlerin uygulanması zordur ve daha fazla geçerlik çalışmaları yapılması gerektiği belirtilen görüşler arasındadır (75). Ayrıca, yürüme bozukluğu olan yaşlı bireylerde ve engellilerde ActivPal gibi akselerometrelerin kullanılabileceği (68), fakat SWA gibi ölçüm araçlarının ise, ciddi komorbiditesi olan kullanıcılarda tutarsız sonuçlar verdiği belirtilmiștir $(76,77)$.

\section{SONUÇ}

Fiziksel aktivite ölçümünde doğru veri elde etmek için hata oranını en aza indirmek önemlidir. $\mathrm{Bu}$ nedenle araştırmanın amacı doğrultusunda kullanılacak yöntemin avantaj ve dezavantajları, sinırlılıkları mutlaka gözönünde bulundurulmalıdır. Anketlerin ucuz maliyetli ve kolay uygulanabilir olması büyük popülasyonlu araştırmalarda kullanılmasını kolaylaştırmaktadır. Fakat hatırlama problemleri ve sorulara tutarsız cevaplar verilmesi, düşük veya yüksek rapor etme olasılığı fiziksel aktivite düzeyinin yanlıs belirlenmesine neden olabilmektedir. Tüm yaş ve özel gruplara uygulanabilirlik özelliği taşıyan pedometre ve akselerometreler ile anketlerde ortaya çıkan birçok sinırlılığın üstesinden gelinebilinir ve hata oranı en aza indirilebilir. Fakat ölçüm aracının maliyeti ve bireyin cihazı kullanabilirliği gibi faktörler de yöntemin kullanım alanlarını sınırlayabilir. Sonuç olarak FA'yı tek bir ölçüm aracıyla tüm yönleriyle değerlendirmek zordur ve sübjektif, objektif yöntemlerin birlikte tercih edilmesi ölçüm araçlarının birçok sınırlılığını ortadan kaldırabilmektedir.

\section{KAYNAKLAR}

1. Caspersen CJ, Powell KE, Christenson GM. Physical activity, exercise, and physical ftness: defnitions and distinctions for health-related research. Public Health Rep. 1985;100(2):126-31.

2. Gibbs DD. Sir John Floyer, M.D. (1649-1734). Br Med J. 1969;1(5638):242-5.

3. Haskell WL. Physical activity by self-report: a brief history and future issues. $J$ Phys Act Health. 2012;9(Suppl 1):S5-10.

4. Morris JN, Heady JA, Raffle PA, et al. Coronary heartdisease and physical activity of work. Lancet. 1953;262(6795):1053-7.

5. Morris JN, Heady JA, Raffle PAB, et al. Coronary heartdisease and physical activity of work. Lancet. 1953;262(6796):1111-20.

6. Pate RR, O'Neill JR, Lobelo F. The evolving definition of "sedentary". Exerc Sport Sci Rev. 2008;36(4):173-8.

7. World Health Organization. Global Recommendations on Physical Activity for Health. Geneva: WHO; 2010.

8. Sedentary Behaviour Research Network. Letter to the editor: Standardized use of the terms "sedentary" and "sedentary behaviours". Appl Physiol Nutr Metab. 2012;37(3):540-2.

9. Owen N, Sparling PB, Healy GN, et al. Sedentary behavior: emerging evidence for a new health risk. Mayo Clin Proc. 2010;85(12):1138-41.

10. Gibbs BB, Hergenroeder AL, Katzmarzyk PT, et al. Definition, measurement, and health risks associated with sedentary behavior. Med Sci Sports Exerc. 2015;47(6):1295-300.

11. Strath SJ, Kaminsky LA, Ainsworth BE, et al. Guide to the assessment of physical activity: Clinical and research applications: a scientific statement from the American Heart Association. Circulation. 2013;128(20): 2259-79.

12. Migueles JH, Cadenas-Sanchez C, Ekelund U, et al. Accelerometer data collection and processing criteria to assess physical activity and other outcomes: a systematic review and practical considerations. Sports Med. 2017;47(9):1821-45.

13. Durstine JL, Gordon B, Wang Z, et al. Chronic disease and the link to physical activity. J Sport Health Sci. 2013;2(1):3-11.

14. Tudor-Locke C, Craig CL, Aoyagi Y, et al. How many steps/day are enough? For older adults and special populations. Int J Behav Nutr Phys Act. 2011;8:80.

15. Paul DR, Kramer M, Moshfegh AJ, et al. Comparison of two different physical activity monitors. BMC Med Res Methodol. 2007; 7:26.

16. Can S, Gündüz N, Arslan E, et al. Multi-instrument assessment of physical activity in female office workers. Int $J$ Occup Med Environ Health. 2016;29(6):937-45. 
17. Knowlden A. Measurement of physical activity for health promotion and education research. Arch Exerc Health Dis. 2015;5(1-2):338-45.

18. Schneider PL, Crouter SE, Lukajic O, et al. Accuracy and reliability of 10 pedometers for measuring steps over a 400-m walk. Med Sci Sports Exerc. 2003;35(10):1779-84.

19. Sallis JF. Measuring physical activity: practical approaches for program evaluation in Native American communities. J Public Health Manag Pract. 2010;16(5):404-10.

20. UenoI DT, Sebastião É, Corazza DI, et al. Methods for assessing physical activity: a systematic review focused on older adults. Braz J Kinanthrop Hum Perform. 2013;15(2):256-65.

21. Crouter SE, Schneider PL, Karabulut M, et al. Validity of 10 electronic pedometers for measuring steps, distance, and energy cost. Med Sci Sports Exerc. 2003;35(8):1455-60.

22. Karaca A. Fiziksel aktivite değerlendirme yöntemleri. 1. Basım. Ankara: Spor Yayınevi ve Kitabevi; 2017.

23. Scheers T, Philippaerts R, Lefevre J. Variability in physical activity patterns as measured by the SenseWear Armband: how many days are needed? Eur J Appl Physiol. 2012;112(5):1653-62.

24. Ward DS, Evenson KR, Vaughn A, et al. Accelerometer use in physical activity: Best practices and research recommendations. Med Sci Sports Exerc. 2005;37(11 Suppl):S582-8.

25. Herrmann SD. Physical activity measurement. In: BE Ainsworth, CA Macera, Eds. Physical Activity and Public Health Practice. Boca Raton, FL: CRC Press, Taylor \& Francis Group; p.179-95; 2012.

26. Sasaki JE, da Silva KS, da Costa BGG, et al. Measurement of physical activity using accelerometers. In: JK Luiselli, AJ Fischer, Eds. Computer-Assisted and Web-Based Innovations in Psychology, Special Education, and Health. London: Academic Press, Elsevier; p.33-60; 2016.

27. Clark CC, Barnes CM, Stratton G, et al. A review of emerging analytical techniques for objective physical activity measurement in humans. Sports Med. 2017;47(3):439-47.

28. Trost SG, McIver KL, Pate RR. Conducting accelerometer-based activity assessments in fieldbased research. Med Sci Sports Exerc. 2005;37(11 Suppl):S531-43.

29. Borgundvaag E, McIsaac M, Borghese MM, et al. Imputing accelerometer nonwear time when assessing moderate to vigorous physical activity in children. J Phys Act Health. 2017;14(11):852-60.

30. Rowlands AV. Accelerometer assessment of physical activity in children: an update. Pediatr Exerc Sci. 2007;19(3):252-66.

31. Bassett DR Jr, Rowlands A, Trost SG. Calibration and validation of wearable monitors. Med Sci Sports Exerc. 2012;44(1 Suppl 1):S32-8.
32. Sasaki JE, John D, Freedson PS. Validation and comparison of ActiGraph activity monitors. J Sci Med Sport. 2011;14(5): 411-6.

33. Jacobi D, Perrin AE, Grosman N, et al. Physical activity-related energy expenditure with the RT3 and TriTrac accelerometers in overweight adults. Obesity (Silver Spring). 2007;15(4):950-6.

34. Ainsworth B, Cahalin L, Buman M, et al. The current state of physical activity assessment tools. Prog Cardiovasc Dis. 2015;57(4):387-95.

35. Warren JM, Ekelund U, Besson $\mathrm{H}$, et al. Assessment of physical activity - a review of methodologies with reference to epidemiological research: a report of the exercise physiology section of the European Association of Cardiovascular Prevention and Rehabilitation. Eur J Cardiovasc Prev Rehabil. 2010;17(2):127-39.

36. Hart TL, Swartz AM, Cashin SE, et al. How many days of monitoring predict physical activity and sedentary behaviour in older adults? Int J Behav Nutr Phys Act. 2011;8:62.

37. Falck RS, Landry GJ, Brazendale K, et al. Measuring physical activity in older adults using MotionWatch 8 actigraphy: how many days are needed? J Aging Phys Act. 2017;25(1):51-7.

38. Troiano RP, McClain JJ, Brychta RJ, et al. Evolution of accelerometer methods for physical activity research. Br J Sports Med. 2014;48(13):1019-23.

39. Sandroff BM, Motl RW, Pilutti LA, et al. Accuracy of StepWatch $^{\text {TM }}$ and ActiGraph accelerometers for measuring steps taken among persons with multiple sclerosis. PLoS One. 2014;9(4):e93511.

40. Tudor-Locke C, Barreira TV, Schuna JM Jr, et al. Improving wear time compliance with a 24-hour waist-worn accelerometer protocol in the International Study of Childhood Obesity, Lifestyle and the Environment (ISCOLE). Int J Behav Nutr Phys Act. 2015;12:11.

41. Kozey-Keadle S, Libertine A, Lyden K, et al. Validation of wearable monitors for assessing sedentary behavior. Med Sci Sports Exerc. 2011;43(8):1561-7.

42. Kozey-Keadle S, Shiroma EJ, Freedson PS, et al. Impact of accelerometer data processing decisions on the sample size, wear time and physical activity level of a large cohort study. BMC Public Health. 2014;14:1210.

43. McKenzie TL. 2009 C. H. McCloy Lecture. Seeing is believing: observing physical activity and its contexts. Res Q Exerc Sport. 2010;81(2):113-22.

44. Hardy LL, Hills AP, Timperio A, et al. A hitchhiker's guide to assessing sedentary behaviour among young people: deciding what method to use. J Sci Med Sport. 2013;16(1):28-35.

45. McKenzie TL, Smith NJ. Studies of physical education in the United States using SOFIT: a review. Res $Q$ Exerc Sport. 2017;88(4):492-502. 
46. Prince SA, Adamo KB, Hamel ME, et al. A comparison of direct versus self-report measures for assessing physical activity in adults: a systematic review. Int J Behav Nutr Phys Act. 2008;5:56.

47. Bauman A, Bull F, Chey T, et al. The International Prevalence Study on Physical Activity: results from 20 countries. Int J Behav Nutr Phys Act. 2009;6:21.

48. Craig CL, Marshall AL, Sjöström M, et al. International Physical Activity Questionnaire: 12-country reliability and validity. Med Sci Sports Exerc. 2003;35(8):1381-95.

49. Ainsworth BE, Haskell WL, Herrmann SD, et al. 2011 Compendium of Physical Activities: a second update of codes and MET values. Med Sci Sports Exerc. 2011;43(8):1575-81.

50. Öztürk M. Üniversitede eğitim-öğretim gören öğrencilerde uluslararası fiziksel aktivite anketinin geçerliliği ve güvenirliği ve fiziksel aktivite düzeylerinin belirlenmesi. Hacettepe Üniversitesi Sağlık Bilimleri Enstitüsü Fizik Tedavi ve Rehabilitasyon Programı Yüksek Lisans Tezi. Ankara: Hacettepe Üniversitesi; 2005.

51. Karaca A, Can S, Gökçe İ. Reliability and validity of turkish version of International Physical Activity Questionnaire-Short Form in obese adults. 15th International Sport Sciences Congress. Book of Abstracts. 2017 Nov 15-18; Antalya, Turkey. p. 13689.

52. Karaca A, Ergen E, Koruç Z. Fiziksel aktivite değerlendirme anketi (FADA) güvenirlik ve geçerlik çalışması. Hacettepe JSS. 2000;11(1):17-28.

53. Karaca A, Turnagöl HH. Çalışan bireylerde üç farklı fiziksel aktivite anketinin güvenirliği ve geçerliği. Hacettepe JSS. 2007;18(2):68-84.

54. Bull FC, Maslin TS, Armstrong T. Global physical activity questionnaire (GPAQ): nine-country reliability and validity. $J$ Phys Act Health. 2009;6(6):790-804.

55. Friedenreich CM, Cook LS, Magliocco AM, et al. Casecontrol study of lifetime total physical activity and endometrial cancer risk. Cancer Causes Control. 2010;21(7):1105-16.

56. Dolan SH, Williams DP, Ainsworth BE, et al. Development and reproducibility of the bone loading history questionnaire. Med Sci Sports Exerc. 2006;38(6):1121-31.

57. Eaton DK, Kann L, Kinchen S. Youth risk behavior surveillance - United States, 2007. MMWR Surveill Summ. 2008;57(4):1-131.

58. Troiano RP, Berrigan D, Dodd KW, et al. Physical activity in the United States measured by accelerometer. Med Sci Sports Exerc. 2008;40(1):1818.

59. Johnson MF, Sallis JF, Hovell MF. Self-report assessment of walking: effects of aided recall instructions and item order. Meas Phys Educ Exerc Sci. 2000;4(3):141-55.
60. Can S, Arslan E, Ersöz G. Güncel bakış açısı ile fiziksel aktivite. Spormetre AÜ Spor Bil Fak 2014;12(1):1-10.

61. Bouchard C, Tremblay A, Leblanc C, et al. A method to assess energy expenditure in children and adults. $\mathrm{Am}$ J Clin Nutr. 1983;37(3): 461-7.

62. Arslan E, Aras D, Can S. Sporcu ve sedanter kadınlarda günlük enerji harcaması ve fiziksel aktivite düzeylerinin karşılaştırılması. Spormetre Beden Eğitimi ve Spor Bilimleri Dergisi. 2016;14(1):53-61.

63. Sylvia LG, Bernstein EE, Hubbard JL, et al. Practical guide to measuring physical activity. J Acad Nutr Diet. 2014;114(2):199-208.

64. Andreacci JL, Dixon CB, McConnell TR. Validation of SenseWear (R) Armband to assess energy expenditure in children ranging in body size. Med Sci Sports Exerc. 2006;38(5):255.

65. Calabró MA, Welk GJ, Eisenmann JC. Validation of the SenseWear Pro Armband algorithms in children. Med Sci Sports Exerc. 2009;41(9):1714-20.

66. Castillo-Retamal M, Hinckson EA. Measuring physical activity and sedentary behaviour at work: a review. Work. 2011;40(4):345-57.

67. Grant PM, Dall PM, Mitchell SL, et al. Activity-monitor accuracy in measuring step number and cadence in community-dwelling older adults. J Aging Phys Act. 2008; 16(2):201-14.

68. Taraldsen K, Askim T, Sletvold O, et al. Evaluation of a body-worn sensor system to measure physical activity in older people with impaired function. Phys Ther. 2011;91(2):277-85.

69. Can S, Karaca A, Arslan E, et al. Physical activity measurement by SWA in employees: weekdays and weekend. Phys Activ Rev. 2017;5:167-75.

70. Campbell KL, Crocker PR, McKenzie DC. Field evaluation of energy expenditure in women using Tritrac accelerometers. Med Sci Sports Exerc. 2002;34(10):1667-74.

71. Villeneuve PJ, Jerrett M, Su JG, et al. Association of residential greenness with obesity and physical activity in a US cohort of women. Environ Res. 2018;160:372-84.

72. Tyo BM, Bassett DR Jr, Coe DP, et al. Effect of BMI on pedometers in early adolescents under free-living conditions. Med Sci Sports Exerc. 2013;45(3):569-73.

73. Lassenius O, Akerlind I, Wiklund-Gustin L, et al. Selfreported health and physical activity among community mental healthcare users. J Psychiatr Ment Health Nurs. 2013;20(1): 82-90.

74. Nyboe L, Lund H. Low levels of physical activity in patients with severe mental illness. Nord J Psychiatry. 2013;67(1):43-6.

75. Vancampfort D, Correll CU, Probst M, et al. A review of physical activity correlates in patients with bipolar disorder. J Affect Disord. 2013;145(3):285-91. 
76. Tierney M, Fraser A, Purtill $H$, et al. Study to determine the criterion validity of the SenseWear Armband as a measure of physical activity in people with rheumatoid arthritis. Arthritis Care Res (Hoboken). 2013;65(6):888-95.
77. Hill K, Dolmage TE, Woon L, et al. Measurement properties of the SenseWear armband in adults with chronic obstructive pulmonary disease. Thorax. 2010;65(6):486-91. 